\section{Online Health Information and Health Changes: A Gender Approach to Technology and Health Empowerment among Jewish Women in Israel}

\author{
Rita S Mano* \\ Department of Human Services, University of Haifa, Israel
}

\begin{abstract}
More and more people are seeking information about health issues on the internet, thus underscoring the importance of technology-embedded information regarding health concerns. In this study, we examine how gender affects the search for health information online and influences changes in health behavior. A total of 2008 individuals who returned questionnaires constituted an initial representative sample. Of these, $1406(67.6 \%)$ were identified as internet users from the Jewish population $(46.5 \%$ men and $53.5 \%$ women). Using a logistic regression analysis, we show that being a Jewish woman in Israel has (a) a significant impact on use of online health information and (b) a limited effect on health behavior. More specifically, we show that online health information induces positive changes regarding smoking and starting a diet among women. We conclude that gender is a motivating factor in the use of online health information but not necessarily in the initiation of health changes. The theoretical implication of the study is that the conceptual integration of a "gendered" perspective regarding online health information use with health empowerment offers a promising framework for testing the link between online health information and health behavior. The study's practical applications for health management are highlighted as well, since women's role as caregivers serves as a cornerstone for increased health promotion.
\end{abstract}

Keywords: Gendered technology; Health changes; Health empowerment; Internet

\section{Introduction}

Internet use is constantly rising, and access to online health information is seen as an advantage in achieving health literacy and increasing health empowerment [1]. Among internet users, women are reported as highly attracted to Online Health Information (hereafter OHI). In the US, nearly $56 \%$ of women used the internet for

*Corresponding author: Rita S Mano, Department of Human Services, University of Haifa, Israel, Tel: +972 547611608; Email: ritamano@research.haifa.ac.il

Citation: Mano RS (2016) Online Health Information and Health Changes: A Gender Approach to Technology and Health Empowerment among Jewish Women in Israel. J Community Med Public Health Care 3: 023.

Received: August 17, 2016; Accepted: October 21, 2016; Published: November 04, 2016 various purposes and $22.8 \%$ sought out health information, whereas only $17.4 \%$ of men visited health sites [2,3]. For women who do have technology skills, the Internet triggers a learning process and provides basic and often necessary information about health products and services thus increasing health empowerment. The current study focuses on the effect of gender variations in Online Health Information (hereafter $\mathrm{OHI}$ ) and health changes among Israel's Jewish population.

In Israel, $75 \%$ of the Jewish population has access to the internet, and $62 \%$ of the population reported conducting internet health searches [4,5]. According to OECD reports [3], between 2000 and 2012 access to the internet in Israel increased considerably, from $19.7 \%$ to $70.2 \%$. This increase is higher than the increase in other industrial countries during the same period. In Canada, for example, the rate increased from $42.8 \%$ to $80.3 \%$. In EU countries such as Germany and France, internet use increased from $18.4 \%$ in 2000 to $83.5 \%$ in 2012, while internet use in 2012 in Ireland reached $94.6 \%$ and in Sweden $91.69 \%$. In general terms, Israel's overall rate of internet access is lower than the median of $76.13 \%$ reported for the EU zone (28 countries). Since these differences may indicate variations between groups it is interesting to consider the extent to which health empowerment is a gender-specific process that affects $\mathrm{OHI}$ and health changes.

The internet offers a wide range of options for men and women alike by providing immediate results for individuals seeking OHI. The technological and functional features of the internet enable individuals to find health information quickly and efficiently. Yet at the same time, a substantial number of studies have raised concerns that the "technology embedded" internet may affect women and additional social groups who may lack the necessary technical skills or just dislike using Computer-Mediated Communication (CMC) to seek information [6]. Addressing the link between gender $\mathrm{OHI}$ and health changes is especially important because a large segment of Jewish women in Israel seeks to combine work responsibilities and career with the role of family caregiver [7-9]. At the same time, women have been shown to be quite selective in the scope of their internet use. They are likely to search diverse sites [10] and to use information in different ways [11] and for the benefit of various persons, including family and community members [12-14].

In communication and sociological studies the concept of digital divide provides ample evidence for the existence of differences in access and use of internet sources. The "first level" of the digital divide, is caused by low technological skills $[15,16]$ that stem from socioeconomic variations-gender, education, income, occupation and ethnicity. The "second level" digital divide effect [17] occurs when individuals from "weak" social groups fail to benefit from OHI information to improve their health literacy and this may affect their healthcare status $[18,19]$ and health behaviors [20]. In regard to women the "second level" digital divide is closely related to the "gendered" approach of technology $[21,22]$ suggesting that the "masculinity" of technology on platforms generates "gendered" variations in internet access and use [23]. Thus, women may be less willing to embrace health behaviors advocated by various health platforms and/or provided by health care providers [24]. 
A "gendered" approach to women's access to OHI may have important implications for the wellbeing of family and community members [14,25-27] who often rely on women's roles as caretakers to take concrete steps towards better health routines, new health habits and health changes $[28,29]$ increasing the level of Health Empowerment (hereafter HE). HE has many manifestations, including alleviating fears, tracing bothersome symptoms and increasing willingness to adopt new health habits $[27,30,31]$ that can help generate health changes [20] and increase overall wellbeing among community members [7].

The present study examines the link between OHI and women's health empowerment. We draw upon a theoretical link between (a) health empowerment models [28,32] (b) the internet [33] and (c) gender studies $[34,35]$. We contend that variations in the OHI-HE relationship reflect the strain between basic assumptions of Health Empowerment (hereafter HE) theory and the "techno-feminism" approach [36,37]. HE theory suggests that women's caregiving roles will be a strong motivator for using $\mathrm{OHI}$ and for incorporating health changes, whereas the techno-feminism approach suggests the emergence of gendered outcomes.

\section{Background}

Addressing the differences in the gender-OHI link necessitates an interdisciplinary approach. In this study, we combine (a) the Health Empowerment approach (hereafter HE) and (b) the Sociological Diversification Hypothesis (hereafter SDH).

According to the HE approach, $\mathrm{OHI}$ is a valuable route to access information and other resources that increase an individual's willingness to form new health habits. Moreover, HE enables "e-patients" to use health-related products and services to help alleviate bothersome symptoms when there is a health problem $[27,30,31]$. HE has been considered the "holy grail of health promotion" [38] because it takes into consideration both "motivations" and "activation" and assumes that individuals with the skills to access $\mathrm{OHI}$ will be also willing to move forward and "activate" the process by following up on the newfound information and applying it to health behaviors. Accordingly, $\mathrm{HE}$ assumes that when individuals recognize their right to express aspirations and are able to define them in terms of outcome, they develop a critical consciousness of the existing situation. This consciousness increases the sense of self-efficacy [28,39] making individuals willing to take an active role in taking preventative measures and following up on health issues for themselves and others [29]. Perhaps this is why Bandura [28] concluded that evaluating the state of empowerment in health practices necessitates considering "critical consciousness" as an essential element in activating HE, pursuing expected health behaviors and attaining expected health outcomes [20,24,40].

These major theoretical points necessitate considering $\mathrm{OHI}$ and health changes as two distinct aspects of HE that reflect (a) motivations and (b) behaviors. This distinction is important with regard to women's role as healthcare" givers in family and community specially when motivations increase the odds for behaviors involving healthcare concerns [41]. Wilhelm and Bekkers [42] refer to this role as the "principle of that often becomes part of women's daily activities. While it is not clear whether such personal norms stem from other "higher" norms [42] or from some type of "natural order" or "social order" [32], at the very least women's caring expresses a normative order found in many human contexts as described and extended in theories of "moral development" and pro-social reasoning [14].
The theoretical background of communication technology studies indicates that gender may sustain or block exposure to and further use of OHI $[22,43]$ depending on whether technology-embedded communication is considered "friendly" or "unfriendly" [37,44]. Indeed, gender studies suggest that technology and its applications, including internet platforms, are basically "masculine" and that women are less likely to enjoy its advantages since their internal mental workings, communication needs and preferences differ from those of men $[10,21,37,42]$.

The recently developed Sociological Diversification Hypothesis (SDH) $[16,33]$ represents a significant shift. Contrary to the gendered perspective, $\mathrm{SDH}$ suggests that access to the internet diminishes any second-level digital divide effects. The easy and efficient use of $\mathrm{OHI}$ will be most beneficial for "weak" social groups. Women are more likely to feel the "squeeze" between family/community and work spheres. Access to OHI increases the odds for women to be able to attend to both spheres. As a result, women will be more willing to seek technology-based sources of information since knowledge about health risks and benefits is a strong predictor of an individual's need to exercise control over health practices. Hence, we hypothesize that:

\section{H1: Gender will be related to $\mathrm{OHI}$ access.}

More specifically, we formulate two alternative hypotheses representing the contrary directions proposed by HE and the gendered perspective:

H1a: Being a woman will have a negative effect on OHI use.

H1b: Being a woman will have a positive effect on $\mathrm{OHI}$ use.

\section{Gender and health changes}

$\mathrm{HE}$ is not only about intentions and motivations. It also encompasses individuals' "behaviors" in moving from the information-seeking stage to the stage of following upon newfound information. Translating $\mathrm{OHI}$ into health behaviors is a dynamic process of making health decisions involving willingness to follow up on what is interesting and useful and to connect this to concepts of well-being. To do so, health information must be evaluated while keeping in mind the following conditions [32]. First, information must be relevant and specific to health conditions and symptoms. Second, it must be understood that some means are better than others in facilitating desired health. Third, it is important to acknowledge whether social conditions in the individual's environment enhance or impede application of the desired health goals. All three aspects can be equally effective for women who look after the health concerns of a partner, parents, children or community members.

On the one hand, access to relevant $\mathrm{OHI}$ can even increase the chances of implementing healthier behavior.OHI empowers individuals to take the necessary steps to eliminate a source of concern, since understanding makes it easier to develop a full perspective about one's medical condition. Yet on the other hand according to Bandura [28] individuals are expected to have little incentive to act or persevere in any behaviors in the face of difficulties, especially when they are not certain their actions will produce the desired effects $[28,31,45]$. If the context of technology is gendered women's self-capacity in going from the OHI stage to the stage of health changes will necessitate combining information from various sources, e.g., online health platforms, kiosks and health communities [32]. For women, getting involved in a health change process necessitates taking responsibility, asking questions and communicating personal needs [46], and seeking out 
additional background information using additional sources of health information [29] regarded as traditional and/or complementary [16].

This "dual information process" involves a combination of the consumer-oriented and the community approaches $[29,47]$. This combinationmay increase the potential for contradictions between information provided by community members experiences and that provided by OHI [44]. Moreover, assuming that technology-embedded information affects decisions in health, as suggested by the "techno-feminism" approach, women are less prone to count on OHI. Accordingly, they may decline to use it as a source that successfully triggers activation of health changes. We therefore hypothesize that:

$\mathrm{H} 2$ : Gender will be related to health changes following access to OHI.

More specifically, we formulate two alternative hypotheses representing the contrary directions proposed by HE and by the gendered perspective regarding the relationship between gender and health changes:

H2a: Being a woman will increase the likelihood of health changes following access to OHI.

H2b: Being a woman will decrease the likelihood of health changes following access to OHI.

\section{Socioeconomic effects}

Socioeconomic factors shape motivations and behaviors and influence the likelihood of acting upon newfound information [45,48]. Moreover, socio-economic factors increase individuals' potential to surf the internet for general as well as specific information, including information related to health and medical issues [49]. Age is a proxy for internet skills [17]. Elderly people are less likely to know how and to what extent they can use the internet and search engines [44]. Yet since health usually deteriorates with age, older individuals may have a stronger motivation to seek online health-related information and participate in health group discussions [50]. Income: Studies on discrepancies in OHI use have found differences among groups based on their socioeconomic status. The likelihood of searching for health information online was inversely associated with income [33]. Education: Understanding medical information and conforming to prescriptions and instructions necessitates appropriate educational skills. Moreover, understanding $\mathrm{OHI}$ when visiting a website or participating in health-related virtual communities requires the cognitive skills and language related to the search itself $[13,51]$. When education levels and internet skills are high [52,53], OHI can positively affect health behaviors.

\section{Methods}

\section{Research design}

The Unit of Statistical Services at the University of Haifa surveyed an initial sample based on landline phone numbers drawn from the list of 361 localities in Israel. A telephone survey yielded 4100 individuals ranging in age from 18-75 (Appendix 1). Of these, 2008 completed the questionnaires (return rate of $50.2 \%)$. A total of $72.7 \%(n=1,457)$ had access to a computer at home (Appendix 2). We excluded a small number of Arabic-speaking individuals from the analysis. The study's sample comprised $46.5 \%$ men and $53.5 \%$ women. Of these, $71.3 \%$ were married, $5.5 \%$ were widows, $5.5 \%$ were divorced and $17 \%$ were single/never married. Their average age was 46.9 years old $(\mathrm{SD}=16.9)$, their mean education level was 13.42 years $(\mathrm{SD}=3.38)$ and their average number of children was $3.11(\mathrm{SD}=0.76)$.

\section{Questionnaire}

The structured questionnaire included socio-demographic information, extent of use of different media sources to search for health and medical information and perceived effect of internet exposure to health information on changing health routines, indicating health empowerment. Questionnaires were completed over the phone. Five to eight interviewers from the Unit of Statistical Services' pool of students conducted the interviews, under the supervision of experienced advisors from the unit. The first 200 full questionnaires were analyzed for quality of questionnaire items. The information extracted from the structured questionnaire was uploaded to the SPSS statistical package, which the authors used to analyze the data.

\section{Variables}

To measure OHI access, we asked respondents to indicate their frequency of searching for online health information about seven topics (vaccines, high blood pressure, hospitals and doctors, quitting smoking, diet and healthy food and sun protection) on a Likert scale ranging from $1=$ never to $5=$ very frequently. Responses to the items were converted into a single scale by summating responses (scale mean $=12.25, \mathrm{SD}=4.89, \alpha=.73$ ). Health changes were measured by participants' responses to the following statements: $\mathrm{OHI}$ "influenced my health routine"; "convinced me to start engaging in physical activity"; "convinced me to start dieting"; "convinced me to stop smoking"; "helped me cope with a chronic disease" "convinced me to change my physician" and "helped me discontinue a treatment recommended by a physician". Demographic variables included Age (years); Gender (1=Female); Marital Status (1=Married); Number of Children. Socioeconomic variables included Education (years) and Income (New Israeli shekels).

\section{Findings}

First, we tested for differences in internet access and use among the general sample across the study's dependent and independent variables.

The T-test values in table 1 indicate that, as expected, access to the internet in Israel reflects differences in age, gender, education and number of children. Respondents with access to the internet are more likely to be young and more educated and to have fewer children than those without access. Gender differences regarding internet access were significant $\left(0.52 ;{ }^{* *} \mathrm{p}<.01\right)$.

Similarly, the results also point to significant differences between individuals that have chronic illnesses and those that do not. The results of the analysis indicate that the frequency of respondents with a diagnosed medical condition is higher among those without access to the internet than among those with access. Furthermore, differences in satisfaction with one's physician were significant. Individuals using the internet expressed slightly higher levels of satisfaction on two of the four satisfaction parameters (the physician explained my situation using language I could understand; the physician showed empathy).

Next, we used logistic regression modeling to examine the effect of the study's independent variables on internet health information searches.

The findings in Table 2 suggest that all socioeconomic demographic variables, with the exception of marital status, are significant in predicting use of health information. More specifically, older age diminishes the search for information $(B=-17)$, but education $(B=0.07)$ as well as being diagnosed with a chronic illness $(B=0.07)$ increase the 


\begin{tabular}{|c|c|c|}
\hline & No access to internet & Access to internet \\
\hline & $(n=590)$ & $(n=1392)$ \\
\hline \multirow{2}{*}{ Age (years) } & 55.36 & 43.97 \\
\hline & 16.33 & $(15.82)^{\star *}$ \\
\hline \multirow{2}{*}{ Gender (1=Male) } & 0.58 & 0.52 \\
\hline & $(0.49)$ & $(0.39)^{\star *}$ \\
\hline \multirow{2}{*}{ Marital status ( $1=$ Married) } & 0.73 & 0.70 \\
\hline & 0.44 & 0.45 \\
\hline \multirow{2}{*}{ Number of children } & 3.65 & 2.80 \\
\hline & 2.2 & $(1.3)^{\star *}$ \\
\hline \multirow{2}{*}{ Education (Years) } & 11.86 & 14.32 \\
\hline & $(3.74)$ & $(2.75)^{*}$ \\
\hline \multirow{2}{*}{ Chronic illness ( $1=$ Yes) } & 0.34 & 0.68 \\
\hline & $(0.14)$ & $(0.28)^{\star \star \star}$ \\
\hline \multirow{2}{*}{$\begin{array}{l}\text { The physician explained using } \\
\text { language I could understand }\end{array}$} & 3.94 & 4.11 \\
\hline & $(1.38)$ & $(1.23)^{\star \star}$ \\
\hline \multirow{2}{*}{$\begin{array}{l}\text { The physician showed empathy } \\
\text { for my complaints }\end{array}$} & 4.24 & 4.35 \\
\hline & 1.20 & $(1.01)^{*}$ \\
\hline \multirow{2}{*}{$\begin{array}{l}\text { The physician paid attention to } \\
\text { my condition }\end{array}$} & 4.19 & 4.26 \\
\hline & $(1.20)$ & $(1.12)$ \\
\hline \multirow{2}{*}{$\begin{array}{l}\text { The physician shared decisions } \\
\text { about my condition with me }\end{array}$} & 3.89 & 3.96 \\
\hline & (1.41) & (1.30) \\
\hline
\end{tabular}

Table 1: T-test for differences in use of internet access by socioeconomic variables and health attitudes.

${ }^{*} \mathrm{p}<.05 ;{ }^{* *} \mathrm{p}<.01$

\begin{tabular}{|c|c|c|c|}
\hline & B & SE & Beta \\
\hline Age & -0.02 & 0.00 & $-0.17^{* *}$ \\
\hline Gender & -0.57 & 0.13 & $-0.11^{* *}$ \\
\hline Married & 0.11 & 0.21 & 0.02 \\
\hline \# Children & 0.14 & 0.05 & $0.03^{*}$ \\
\hline Education & 0.06 & 0.02 & $0.07^{\star *}$ \\
\hline Chronic illness & 0.32 & 0.12 & $0.07^{*}$ \\
\hline Satisfaction with health provider & 0.12 & 0.03 & $0.01^{* *}$ \\
\hline Constant & 2.84 & 0.80 & \\
\hline Adjusted R square & 0.27 & & \\
\hline
\end{tabular}

Table 2: Ordinary Least Square regression (OLS) predicting OHI search. ${ }^{*} \mathrm{p}<.05 ;{ }^{* *} \mathrm{p}<.01$

odds of searching for information on the Internet. More important, however, is the finding that men are significantly less likely to search for health information than are women $(\mathrm{B}=-11)$. These findings indicate that women are more involved in health matters than men.

Next, we tested the association between empowerment measures following $\mathrm{OHI}$ use.

Table 3 depicts the effects of background characteristics on the probability of health changes, i.e., on the level of HE following access to OHI. The table shows the explained variance (Exp. B) and the significance ( $95 \% \mathrm{CI})$ in parentheses for the effect of (a) a set of socioeconomic variables (age and education) and (b) two conditions related to the HE hypothesis (chronic illness and satisfaction with health care provider). Controlling for the effect of these two sets of variables, we tested the effect of gender (women compared to men). The table reveals several interesting findings.

First, the most prevailing influence on empowerment is related to age differences. All seven items of health-related changes are significantly influenced by differences in age. Second, four out of the seven items-changes in health routine, coping with a chronic disease, starting a diet and starting to engage in physical activity-are related to differences in education. These results indicate the existence of technology effects because age and education are strong indicators of technology skills related to i possible reason is that women's use of the internet use and OHI access. Next, we considered chronic illness and satisfaction with health care providers as two indicators of HE. The findings indicate that having a chronic illness increases the chance of HE in two areas: coping with a chronic illness [Exp. $(B)=2.57$ ] and stopping treatments [Exp. $(B)=1.83$ ]. The findings also imply an ambiguous effect of satisfaction with health care provider, suggesting that the attitudinal component of HE is less effective in generating health change. Gender effects are inconclusive as well. Women's use of OHI affects two HE items: a modest impact on changing health routine $[(\operatorname{Exp} .(B)=1.28)]$ and physical activity $[(\operatorname{Exp} .(B)=1.28)]$ and a weaker effect on starting a diet [(Exp. $(B)=1.20)]$.

The findings indicate that while HE hypotheses do reflect gender variations to some extent, gender fails to predict the positive variations expected by the SDH or the hypotheses developed by the gendered approach. One possible reason is that women's use of the internet is still mostly related to keeping contact with community and family members [16]. Another explanation is that the inclusion of more basic $\mathrm{HE}$ conditions, such as age and education on one hand and a chronic condition and satisfaction with health care provider on the other, limits any possible effects of gendered variations in OHI. In other words, young, educated and healthy Jewish women in Israel who are satisfied with health care are less likely to access and be influenced by OHI. Nevertheless, they do still consult $\mathrm{OHI}$ for some less pervasive HE behaviors, such as going on a diet and changing their health routine.

\section{Discussion}

Individuals are using online health communication more and more but little research attention has been devoted to gender differences in the use of online health information and health behaviors. In this study we considered the extent to which gender affects the likelihood of health changes following access to online health information. We considered this possibility because women are often more involved in the health of their partners, children, larger family unit and community. We obtained our hypotheses from two opposing theories-health empowerment and a gendered approach to technology-in order to formulate the relationship between online health information and health changes among Jewish women in Israel. We assumed that women would be highly motivated to use online health information but that the technological difficulties inherent in the use of online devices might counterbalance the expected positive effect of health empowerment motivations. The results provide indeed evidence of a twofold effect.

According to the health empowerment approach, being a woman should increase access to online health information [29] and hence positively affect health changes consequent to this information. These expectations were partially corroborated. The results support assumptions regarding the significance of health information to women, possibly because women seek to attend to parental, spousal, individual and community health concerns and hence are affected byte motivational aspects of health empowerment [32]. Moreover, assessing 
Citation: Mano RS (2016) Online Health Information and Health Changes: A Gender Approach to Technology and Health Empowerment among Jewish Women in Israel. J Community Med Public Health Care 3: 023.

- Page 5 of 7 •

\begin{tabular}{|c|c|c|c|c|c|c|c|}
\hline & $\begin{array}{l}\text { Change health } \\
\text { routine }\end{array}$ & Start diet & $\begin{array}{l}\text { Start physical } \\
\text { activity }\end{array}$ & Stop smoking & Change physician & $\begin{array}{c}\text { Ceased prescribed } \\
\text { medication }\end{array}$ & $\begin{array}{l}\text { Coping with } \\
\text { chronic disease }\end{array}$ \\
\hline Age & 0.98 & 0.97 & 0.97 & 0.97 & 0.98 & 0.98 & 0.98 \\
\hline \multirow{2}{*}{ Education } & 1.06 & 1.06 & 1.05 & 0.89 & 1.02 & 0.99 & 1.08 \\
\hline & $(1.02-1.10)$ & $(1.02-1.10)$ & $(1.01-1.09)$ & $(0.82-0.97)$ & $(0.96-1.08)$ & $(0.941-0.04)$ & $(1.03-1.13)$ \\
\hline Chronic illness & $(0.95-1.70)$ & $(0.95-1.71)$ & $(0.86-1.46)$ & $(0.63-1.83)$ & $(0.65-1.72)$ & $(1.25-1.69)$ & $(1.86-3.54)$ \\
\hline \multirow{2}{*}{$\begin{array}{l}\text { Satisfaction with health } \\
\text { provider }\end{array}$} & 1 & 1 & 1 & 1.24 & 0.63 & 0.7 & 0.85 \\
\hline & $(0.86-1.15)$ & $(0.86-1.15)$ & $(0.88-1.14)$ & $(0.93-0.65)$ & $(0.52-0.78)$ & $(0.59-0.83)$ & $(0.73-0.98)$ \\
\hline \multirow{2}{*}{ Gender } & 1.28 & 1.2 & 1.28 & 0.8 & 0.4 & 0.98 & 1.17 \\
\hline & $(0.98-1.68)$ & $(0.89-1.60)$ & $(0.98-1.68)$ & $(0.63-1.24)$ & $(0.24-0.66)$ & $(0.63-1.54)$ & $(0.82-1.67)$ \\
\hline
\end{tabular}

Table 3: Logistic regression coefficients predicting health changes following $\mathrm{OHI}$.

the positive impact of being a woman on accessing online health information indicates that Jewish women in Israel have overcome the gendered technology barriers and achieved high levels of technology skills that enable them to access the internet and use OHI. We can thus conclude that gender in Israel is not a source of either first or second level digital divide effects in health [15] for the Jewish population.

A less definitive picture emerges regarding health changes that are the behavioral outcome of health empowerment. The results indicate that people use online health information to implement health changes only to a certain extent. Being a female user of online health information positively affects only some health changes, i.e., diet and health habits, but not health changes related to health care, i.e., those involving changing medication and physicians. It is possible that while women are eager to learn more about health concerns via internet platforms, they may still feel reluctant to consider the use of the internet as an efficient means for activating health changes. The results indicate therefore that a gendered approach and the digital divide hypotheses is still a possibility for women's health behaviors despite access to online health information and thus provide only a partial support of the health empowerment hypothesis [29].

The contrasting findings support the notion that the internet is a valid arena for searching for health-related information and constitutes a major source of health empowerment for women in contributing to their own wellbeing and that of their family and community $[6,29]$, though only to a certain extent [22,37]. The gendered approach may possibly explain why women who do search for health information online perceive of the internet as a "masculine" technology that precludes extensive use and prevents the behavioral translation of such information into comprehensive health-empowered behavior confirming recent studies [34] especially regarding the use of health services [14].

Summarizing the study's findings, we conclude that women's ability to conduct such searches increases their knowledge and promotes their understanding of health-related details relevant to diagnoses and health habits. Yet, it does not provide sufficient motivation to initiate health-related changes, partly because additional socioeconomic factors as well as individual health conditions may act as blocking influences. Moreover, online health information cannot replace faceto-face consultations. Nonetheless, the internet can provide women with valuable health information and increase health literacy. In turn, health literacy can have a significant effect on health empowerment, which can then be applied in relevant situations among family and community members under women's care. We accordingly propose that the link between gender and health behavior should address the discrepancy between a health empowerment approach and a gendered approach. An integrative approach considering the contextual variations presented in the social diversification hypothesis $[16,20]$ increases our theoretical and empirical potential to examine health-related behaviors within a broader social, demographic and possibly ethnicity-dependent environment because it enables to account for variations in the level of resources available to social groups and individuals.

\section{Study Limitations}

The study's findings provide partially confirmation of our assumptions that technology may cause a gendered effect in health empowerment. As the study's conclusions are limited to the Jewish population, future studies should consider this effect as a culturally contingent research topic. The use of cross-sectional samples may increase the potential for fully delineating the factors associated with gender differences in online health information access and health changes.

\section{Recommendations for practice}

The differences between motivational and behavioral aspects in health empowerment are important when considering practical applications for health management. The study highlights the importance of using online services to increase health literacy and introduce health changes. Considering the combined effect of the health empowerment and "gendered" approach benefits to the society are possible at several levels. At the health policy level, health care providers are more likely to effectively channel general and specific health information to promote health when individuals use online services. At the community and family level, community members who often expect women to take care of health-related issues may capitalize on developing women's technology skills and encourage and guide them in accessing online services. Hence it is advisable to allocate resources in the organization of focus groups that consider how women address technology and health concerns. This will increase the potential for fully delineating the factors associated with the differences between motivational and behavioral aspects in health empowerment. This is especially relevant prior to developing new health services, health programs or digital health information devices.

\section{References}

1. Seeman N (2008) Web 2.0 and chronic illness: new horizons, new opportunities. Healthc Q 11: 104-108.

2. Tustin N (2010) The role of patient satisfaction in online health information seeking. J Health Commun 15: 3-17. 
Citation: Mano RS (2016) Online Health Information and Health Changes: A Gender Approach to Technology and Health Empowerment among Jewish Women in Israel. J Community Med Public Health Care 3: 023.

3. OECD (2015) Internet access. OECD, France.

4. Central Bureau of Statistics (2008) Technology use among Israelis over 20 years old. Central Bureau of Statistics, Jerusalem, Israel.

5. TIM (2010) Patterns of use of Internet in Israel.

6. Gurak LJ, Hudson BL (2006) E-Health: Trends and Theory. In: Rice R, Murero M (eds.). The Internet and Health Care: Theory, Research and Practice, Routledge, UK.

7. Wood W, Ridgewat CL (2010) Gender: An Interdisciplinary Perspective. Social Psychology Quarterly 73: 334-339.

8. Sillence $E$, Briggs $P$, Harris PR, Fishwick L (2007) How do patients evaluate and make use of online health information? Social Science \& Medicine 64 1853-1862.

9. Andreassen HK, Bujnowska-Fedak MM, Chronaki CE, Dumitru RC, Pudule I, et al. (2007) European citizens' use of E-health services: a study of seven countries. BMC Public Health 7: 53.

10. Kim DY, Lehto XY, Morrison AM (2007) Gender differences in online travel information search: Implications for marketing communications on the internet. Tourism Management 28: 423-433.

11. Lewis T (2006) Seeking health information on the internet: lifestyle choice or bad attack of cyberchondria? Media Culture \& Society 28: 521-539.

12. Katz JE, Rice RE, Acord SK (2004) E-health networks and social transformations: Expectations of centralization, experiences of decentralization. In: Castells M (ed.). The Network Society: A cross-cultural perspective, Edward Elgar, Cheltenham, UK.

13. Rice RE (2006) Influences, usage, and outcomes of Internet health information searching: multivariate results from the Pew surveys. Int J Med Inform 75: 8-28.

14. Bianco A, Zucco R, Nobile CG, Pileggi C, Pavia M (2013) Parents seeking health-related information on the Internet: cross-sectional study. J Med Internet Res 18: 204

15. Lustria ML, Smith SA, Hinnant CC (2011) Exploring digital divides: an examination of eHealth technology use in health information seeking, communication and personal health information management in the USA. Health Informatics J 17: 224-243.

16. Mesch G, Mano R, Tsamir J (2012) Minority status and health information search: A test of the social diversification hypothesis. Social Science \& Medicine 75: 854-858.

17. Hargittai E, Hinnant A (2008) Digital inequality differences in young adults' use of the Internet. Communication Research 35: 602-621.

18. Joseffson U (2006) Patient's online information-seeking behavior. In: Rice R, Murero M (eds.). The Internet and Health Care: Theory, Research and Methods, Routledge, UK.

19. Fox S, Purcell K (2010) Chronic Disease and the Internet. Pew Internet and American Life Project, Washington, D.C., USA.

20. Mano R (2015) Online health information, situational effects and health changes among e-patients in Israel: A 'push/pull' perspective. Health Expect 18: $2489-2500$

21. Acker J (1992) Gendering organizational theory. In: Mills AJ, Tancred P (eds.). Gendering Organizational Analysis, Sage, Newbury Park, California, USA.

22. Shashaani L (1997) Gender Differences in Computer Attitudes and Use among College Students. Journal of Educational Computing Research 16: $37-51$.

23. Bury R (2010) Women, work and Web 2.0: A case study. New Technology, Work and Employment 25: 223-237.

24. Iverson SA, Howard KB, Penney BK (2008) Impact of internet use on health-related behaviors and the patient-physician relationship: A survey-based study and review. J Am Osteopath Assoc 108: 699-711.

25. Ybarra M, Suman M (2008) Reasons, assessments and actions taken: Sex and age differences in uses of Internet health information. Health Education Research 23: 512-521.

26. Korp P (2006) Health on the Internet: Implications for health promotion Health Educ Res 21: 78-86
27. Dutta-Bergman MJ (2008) Developing a profile of consumer intention, to seek out health information beyond the doctor. Health Marketing Quarterly 21: 91 112

28. Bandura A (2004) Health promotion by social cognitive means. Health Educ Behav 31: 143-164.

29. Dutta-Bergman MJ (2006) Media use theory and internet use for health care. In: Murero M, Rice RE (eds.). The Internet and Health Care: Theory, Research and Practice. Lawrence Erlbaum, New Jersey, USA.

30. Dutta-Bergman MJ (2004) Primary sources of health information: Comparison in the domain of health attitudes, health cognition and health behaviors. Health Commun 16: 273-288.

31. Dutta-Bergman MJ (2004) The impact of completeness and web use motivation on the credibility of health information. Journal of Communication 54 : 253-269.

32. Dutta M, Bodie GD (2008) Web Searching for Health: Theoretical Foundations and Connections to Health Related Outcomes. In: Spink A, Zimmer M (eds.). Web search, Multidisciplinary Perspectives. Springer, London, UK.

33. Mesch GS (2012) Minority Status and the Use of Computer-Mediated Communication - A Test of the Social Diversification Hypothesis. Communication Research 39: 317-337.

34. Cooper J (2006) The digital divide: the special case of gender. Journal of Computer Assisted Learnin 22: 320-334.

35. Joiner R, Littleton K, Chou C, Morahan-Martin J (2006) Gender and information and communication technology. Journal of Computer Assisted Learning 22: $317-319$

36. Wajcman J (1995) Feminist Theories of Technology. In: Jasanoff S, Markle GE, Peterson JC, Pinch T (eds.). Handbook of Science and Technology Studies. Sage Publications, London, UK

37. Wacjman J (2004) Technofeminism. Polity, England, UK.

38. Rissel C (1994) Empowerment: The holy grail of health promotion? Health Promotion International 9: 39-47

39. Bandura A (1997) Self-Efficacy: The Exercise of control. Worth Publishers, New York, USA.

40. Eisenberg M, Berkowtz R (2009) The big approach to information literacy skills.

41. Wasserman IM, Richmond-Abbott M (2005) Gender and the Internet: Causes of Variation in Access, Level, and Scope of Use. Social Science Quarterly 86: $252-270$.

42. Wilhelm MO, Bekkers R (2010) Helping Behavior, Dispositional Empathic Concern, and the Principle of Care. Social Psychology Quarterly 73: 11-32.

43. McAndrew FT, Jeong HS (2012) Who does what on Facebook? Age, sex, and relationship status as predictors of Facebook use. Computers in Human Behavior 28: 2359-2365.

44. van Deursen A, van Dijk JAGM, Peters O (2010) Rethinking Internet skills: The contribution of gender, age, education, Internet experience, and hours online to medium- and content-related Internet skills. Poetics 39: 125-144.

45. Lemire M, Sicotte C, Paré G (2008) Internet use and the logics of personal empowerment in health. Health Policy 88: 130-140.

46. Fox NJ, Ward KJ, O'Rourke AJ (2005) The 'expert patient': Empowerment or medical dominance? The case of weight loss, pharmaceutical drugs and the Internet. Soc Sci Med 60: 1299-309.

47. Rains SA (2007) Perceptions of traditional information sources and use of the world wide web to seek health information: Findings from the health information national trends survey. J Health Commun 12: 667-680.

48. Renahy E, Parizot I, Chauvin P (2008) Health information seeking on the Internet: A double divide? Results from a representative survey in the Paris metropolitan area, France, 2005-2006. BMC Public Health 8: 69.

49. Hardt JH, Hollis-Sawyer L (2007) Older Adults Seeking Healthcare Information on the Internet. Educational Gerontology 33: 561-572. 
Citation: Mano RS (2016) Online Health Information and Health Changes: A Gender Approach to Technology and Health Empowerment among Jewish Women in Israel. J Community Med Public Health Care 3: 023.

- Page 7 of 7 •

50. Bundorf MK, Wagner TH, Singer SJ, Baker LC (2006) Who searches the Internet for health information? Health Serv Res 41: 819-836.

51. Mesch GS, Talmud I (2007) Editorial Comment: e-Relationships-the blurring and reconfiguration of offline and online social boundaries. Information, Communication \& Society 10: 585-589.

\section{Appendix}

\begin{tabular}{|c|c|c|c|}
\hline & General population & Internet users & Internet users for health \\
\hline Men & $45.50 \%$ & $47.20 \%$ & $40.70 \%$ \\
\hline Women & $54.50 \%$ & $52.80 \%$ & $59.30 \%$ \\
\hline Age $18-25$ & $11.20 \%$ & $14.00 \%$ & $13.80 \%$ \\
\hline $26-45$ & $36.70 \%$ & $42.30 \%$ & $44.30 \%$ \\
\hline $46-65$ & $36.60 \%$ & $33.90 \%$ & $33.50 \%$ \\
\hline Income up to 4000 NIS & $14.40 \%$ & $13.90 \%$ & $13.20 \%$ \\
\hline $4001-6000$ & $14.20 \%$ & $16.00 \%$ & $16.00 \%$ \\
\hline $6001-8000$ & $9.20 \%$ & $11.20 \%$ & $10.70 \%$ \\
\hline $8001-10000$ & $6.60 \%$ & $8.80 \%$ & $9.30 \%$ \\
\hline $10001+$ & $8.30 \%$ & $10.80 \%$ & $10.20 \%$ \\
\hline Education high school (part) & $15.50 \%$ & $6.80 \%$ & $5.60 \%$ \\
\hline High school (full) & $31.50 \%$ & $33.10 \%$ & $32.50 \%$ \\
\hline Vocational & $24.50 \%$ & $26.00 \%$ & $25.20 \%$ \\
\hline Academic & $28.60 \%$ & $34.00 \%$ & $36.70 \%$ \\
\hline Chronic condition (1=yes) & $52.30 \%$ & $46.10 \%$ & $46.20 \%$ \\
\hline Jews & $73.10 \%$ & $76.50 \%$ & $76.90 \%$ \\
\hline Muslims & $15.70 \%$ & $13.10 \%$ & $14.10 \%$ \\
\hline Christians & $3.70 \%$ & $3.50 \%$ & $3.20 \%$ \\
\hline Druze & $2.50 \%$ & $2.00 \%$ & $2.10 \%$ \\
\hline Hebrew & $64.00 \%$ & $64.00 \%$ & $68.20 \%$ \\
\hline Russian & $15.00 \%$ & $15.00 \%$ & $14.20 \%$ \\
\hline Arabic & $21.00 \%$ & $21.00 \%$ & $17.60 \%$ \\
\hline
\end{tabular}

Appendix 1: Demographic profile of Internet users and Internet users for health purposes.

\begin{tabular}{|c|c|c|c|c|c|c|c|c|}
\hline & \multicolumn{2}{|c|}{ Internet use } & \multicolumn{2}{|c|}{ No internet use } & \multicolumn{2}{|c|}{ Internet use } & \multicolumn{2}{|c|}{ No internet use } \\
\hline & $\mathrm{N}$ & $\%$ & $\mathrm{~N}$ & $\%$ & $\mathrm{~N}$ & $\%$ & $\mathrm{~N}$ & $\%$ \\
\hline & \multicolumn{4}{|c|}{ Online health services for appointments } & \multicolumn{4}{|c|}{ Online health services for updates } \\
\hline Non-Jews & 277 & 79.9 & 70 & 20.1 & 298 & 82 & 116 & 18 \\
\hline Jews & 686 & 64.7 & 374 & 35.3 & 660 & 66.9 & 326 & 33.1 \\
\hline Men & 456 & 68.7 & 207 & 31.3 & 495 & 74.6 & 168 & 25.4 \\
\hline Women & 506 & 68.2 & 236 & 31.8 & 490 & 66 & 253 & 34 \\
\hline Age18-29 & 211 & 71.7 & 84 & 28.3 & 223 & 75.7 & 72 & 24.3 \\
\hline $30-39$ & 200 & 62.5 & 120 & 37.5 & 189 & 58.9 & 132 & 41.1 \\
\hline $40-49$ & 185 & 69.6 & 81 & 30.4 & 190 & 71.3 & 76 & 28.7 \\
\hline $50-59$ & 165 & 67.7 & 79 & 32.3 & 178 & 73 & 66 & 27 \\
\hline $60-60$ & 113 & 68.2 & 53 & 31.8 & 121 & 72.6 & 46 & 27.4 \\
\hline $70-79$ & 60 & 72.7 & 23 & 27.3 & 59 & 71.2 & 24 & 28.8 \\
\hline $80+$ & 15 & 88.3 & 2 & 11.7 & 15 & 88.3 & 2 & 11.7 \\
\hline Education- 12 years & 402 & 72.9 & 149 & 27.1 & 409 & 74.3 & 142 & 25.7 \\
\hline $13-16$ & 367 & 68.9 & 166 & 31.1 & 377 & 70.8 & 156 & 29.2 \\
\hline $17+$ & 186 & 59.4 & 127 & 40.6 & 190 & 60.6 & 124 & 39.4 \\
\hline Not employed & 298 & 72 & 116 & 28 & 291 & 70.2 & 123 & 29.8 \\
\hline Employed & 660 & 66.9 & 326 & 33.1 & 690 & 70 & 296 & 30 \\
\hline
\end{tabular}

Appendix 2: Distribution differences between Internet users and non-users of online health information and online services used for (a) making appointments and (b) updates. 